\title{
Feminicídio: a cobertura da Folha de S. Paulo a partir da Teoria do Enquadramento
}

\author{
Leonor Graciela Natansohn' \\ Juliana Lopes de Brito²
}

\section{Resumo}

O objetivo deste artigo é fazer uma análise da cobertura jornalística de casos de feminicídio no jornal impresso Folha de S. Paulo. O recorte desse trabalho foram as notícias publicados nas páginas desse jornal em dois blocos temporais, um primeiro que vai de 2004 a 2007 e um segundo na década posterior à promulgação da Lei Maria da Penha e que abrange de 2014 a 2017. Através dessa amostra, pretendia-se verificar os enquadramentos presentes nos dois períodos, possíveis mudanças e continuidades, através da perspectiva teórica do enquadramento. Após a análise de 100 textos noticiosos, publicados na editoria Cotidiano desse jornal, foram identificados 13 tipos de enquadramentos e uma mudança nos dois primeiros meses do segundo semestre de 2017.

Palavras-chave: Jornalismo impresso. Feminicídio. Enquadramento.

\section{Feminicide: the coverage of Folha de S. Paulo through the Theory of the Framework}

\begin{abstract}
The purpose of this article is to analyze the journalistic coverage of femicide cases in the printed newspaper Folha de S. Paulo. The frame of this work were the news

1 Jornalista graduada pela Universidad Nacional de La Plata, doutora pelo Programa de Pós-Graduação em Comunicação e Cultura Contemporâneas da Universidade Federal da Bahia (PósCom/UFBA), professora do PósCom e da Faculdade de Comunicação da UFBA (Facom/UFBA) e coordenadora do Grupo de Pesquisa em Gênero, Tecnologias Digitais e Cultura (Gig@/UFBA).

2 Jornalista graduada pela Facom/UFBA e mestre pelo Programa de Pós-Graduação em Comunicação e Cultura Contemporâneas da Universidade Federal da Bahia (PósCom/UFBA). Pesquisadora do Grupo de Pesquisa em Gênero, Tecnologias Digitais e Cultura (Gig@/UFBA), onde desenvolveu pesquisa de mestrado com apoio da Fundação de Amparo à Pesquisa do Estado da Bahia (Fapesb).
\end{abstract}

Revista Pauta Geral-Estudos em Jornalismo, Ponta Grossa, vol. 6, n. 2, p. 70-89, Jul/Dez, 2019. 


\section{REVISTA PAUTA GERAL}

\section{ESTUDOS EM JORNALISMO}

10.5212/RevistaPautaGeral.v.6.i2.0005

published on the pages of this newspaper in two time blocks, a first from 2004 to 2007 and a second after Maria da Penha's law, covering from 2014 to 2017. Through this sample, it was intended to verify the frameworks present in both periods, possible changes and continuities, through the theoretical perspective of the framework. After analyzing 100 news articles published in Cotidiano, 13 types of frames were identified and also a change in the first two months of the second half of 2017.

Keywords: Printed Newspaper. Feminicide. Framework.

\section{Introdução}

Feminicídio é um termo que designa o assassinato de mulheres em contextos de desigualdade de gênero, pela condição de ser mulher. Foi cunhado nos anos 2000, mas seu "debut" na sociedade brasileira deu-se a partir da Lei $n . \stackrel{0}{13.104}$, popularmente chamada de "Lei do Feminicídio", sancionada pela presidente Dilma Rousseff em nove de março de 2015, um dia após a comemoração do Dia Internacional da Mulher. A alteração na legislação tornou este tipo de homicídio qualificado, inserindo-o no quadro dos crimes hediondos, aumentando, assim, sua punição. Outro efeito, simbólico, foi o de expor a violência contra a mulher como um problema que envolve desigualdade de poder entre os gêneros.

A antropóloga mexicana Marcela Lagarde Y de Los Ríos (2008) foi a primeira a dar maior alcance ao vocábulo "feminicídio", entendido por ela como o genocídio contra as mulheres que acontece quando as condições históricas geram práticas sociais que permitem atentados violentos contra a integridade, saúde, liberdades e a vida de meninas e mulheres. Esta concepção partiu da observação desta pesquisadora de uma sucessão de mortes violentas de mulheres em seu país e na América Latina. A expressão vem de "femicídio", usada pela primeira vez em 1976, em um julgamento realizado no Tribunal Internacional de Crimes contra Mulheres em Bruxelas, e resgatada em 1992 por Diana Russell e Jill Radford no livro Femicide: The Politics of Woman Killing, no qual as autoras defendem a não acidentalidade da morte violenta de mulheres. Na ocasião da tradução desta obra para o espanhol, as autoras pediram a Lagarde para escrever uma discussão sobre o caso mexicano, e então a antropóloga decidiu trocar a tradução de "femicide", que seria "femicídio" (homicídio contra a mulher), por "feminicídio" (conjunto de violações aos direitos humanos das mulheres, que culmina no homicídio), imprimindo um sentido político. Em 2006, a tradução para o espanhol do livro de Russell e Radford recebeu o 2019. 


\section{REVISTA PAUTA GERAL}

\section{ESTUDOS EM JORNALISMO}

10.5212/RevistaPautaGeral.v.6.i2.0005

título Feminicidio. La Politica Del Asesinato de Las Mujeres, e, a partir disto, a expressão difundiu-se.

O vocábulo e a lei aos poucos estão se tornando conhecidos dos brasileiros, no entanto o feminicídio sempre foi um tipo de acontecimento próximo do cotidiano da população, aparecendo constantemente no noticiário, produzindo vítimas dos mais variados perfis sociais. Com o objetivo de sistematizar o tratamento dado aos crimes de feminicídio no Brasil antes e depois da lei, revisamos artigos que abordavam a temática e apresentamos a seguir uma síntese no Quadro 1 - Feminicídio no Brasil. Na primeira coluna temos uma localização do tipo antes e depois da lei, enquanto na segunda coluna procuramos apontar os principais pontos do respectivo período, incluindo também alguns dados relacionados a esse tipo de crime.

\section{Quadro I - Feminicídio no Brasil}

Antes da Lei do

Feminicídio
- Era punido como homicídio (art. 121 do Código Penal). A depender do contexto, poderia ser enquadrado como homicídio qualificado por motivo torpe (inciso I do $\S 2^{\circ}$ do art. 121) ou fútil (inciso II) ou ainda em virtude de dificuldade da vítima de se defender (inciso IV) ${ }^{3}$

- Até os anos 1970 era comum os juris serem benevolentes com os maridos que alegavam adultério como motivação do crime, pois teriam agido em legítima defesa da honra ${ }^{4}$

- Tornou-se homicídio qualificado e crime hediondo

Após a Lei do Feminicídio - A pena aumentou de seis a 20 anos para de 12 a 30 anos, podendo ser aumentada para até 45 anos de prisão

- Situação de violência doméstica e familiar

- Menosprezo ou discriminação à condição de mulher

3 ORTEGA, Flávia Teixeira. Feminicídio (art. 121, $\S 2^{\circ}, \mathrm{VI}$, do CP). Jusbrasil, 2016. Disponível: https://bit.ly/2v7d0dw. Acesso em: 10 set. 2017.

${ }^{4}$ Eluf (2002, p. 163 e 164 apud ROSA, 2010, p. 57 e 58).

Revista Pauta Geral-Estudos em Jornalismo, Ponta Grossa, vol. 6, n. 2, p. 70-89, Jul/Dez, 2019. 


\section{REVISTA PAUTA GERAL}

\section{ESTUDOS EM JORNALISMO}

10.5212/RevistaPautaGeral.v.6.i2.0005

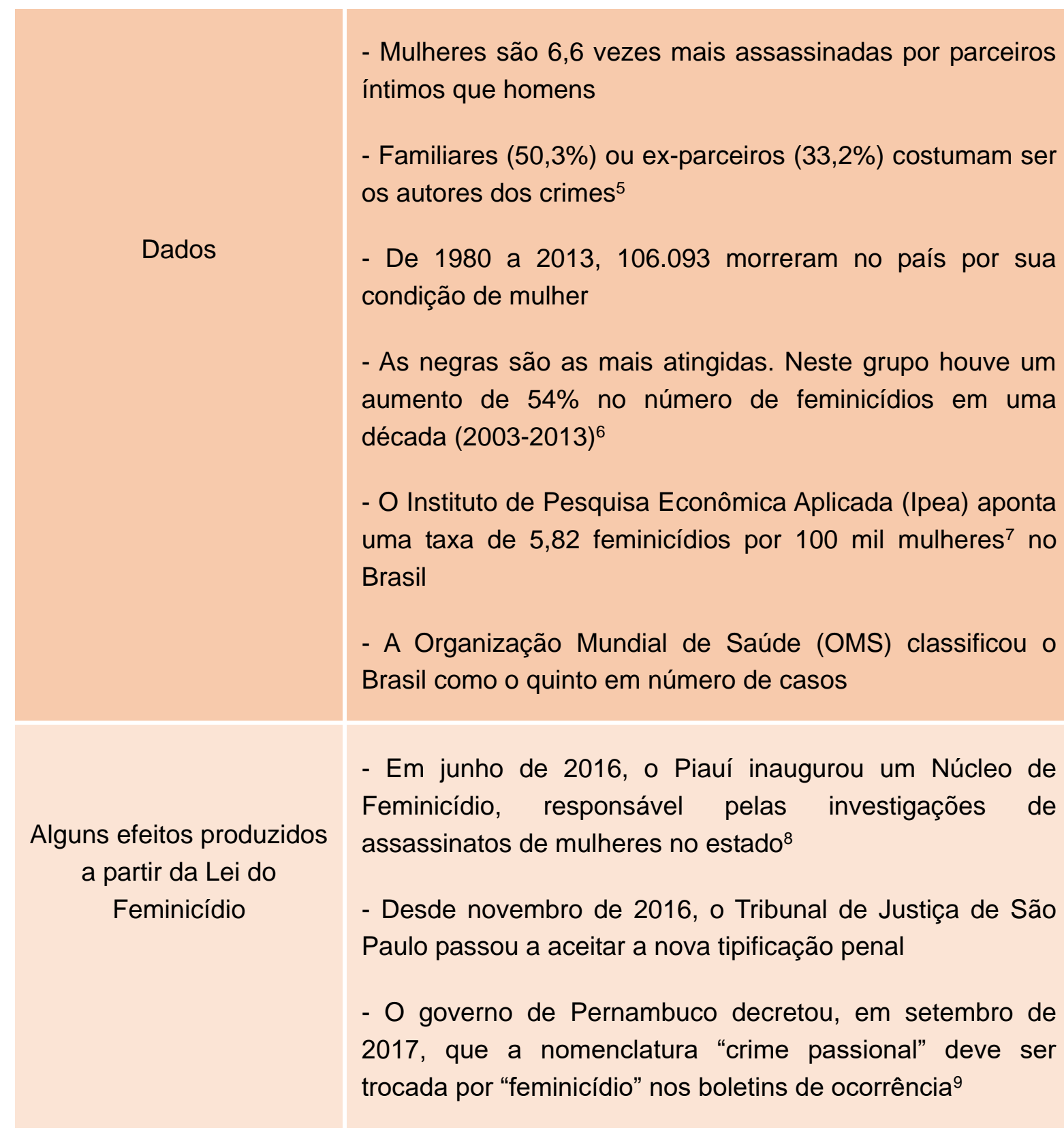

${ }_{5}$ MARTINS, Helena. Taxa de feminicídios no Brasil é a quinta maior do mundo. Agência Brasil, Brasília, 27 ago. 2017. Disponível: https://bit.ly/2w9dbpA. Acesso em: 06 set. 2017

6 Nações Unidas Brasil. ONU: Taxa de feminicídios no Brasil é quinta maior do mundo; diretrizes nacionais buscam solução. Nações Unidas Brasil, 12 abr. 2016. Disponível: https://bit.ly/1WnzObo. Acesso em: 02 set. 2017.

7 GARCIA, Leila Posenato. Violência contra a mulher: feminicídios no Brasil. IPEA, 2013. Disponível: https://bit.ly/1AD5lax. Acesso em: 06 set. 2017.

8 COSTA, Lorenna. Governo do Piauí inaugural Delegacia da Mulher e Núcleo de Feminicídio. Compromisso e Atitude, 24 jun. 2016. Disponível: https://bit.ly/32keEam. Acesso em: 06 set. 2017.

Revista Pauta Geral-Estudos em Jornalismo, Ponta Grossa, vol. 6, n. 2, p. 70-89, Jul/Dez, 2019. 


\section{REVISTA PAUTA GERAL}

\section{ESTUDOS EM JORNALISMO}

10.5212/RevistaPautaGeral.v.6.i2.0005

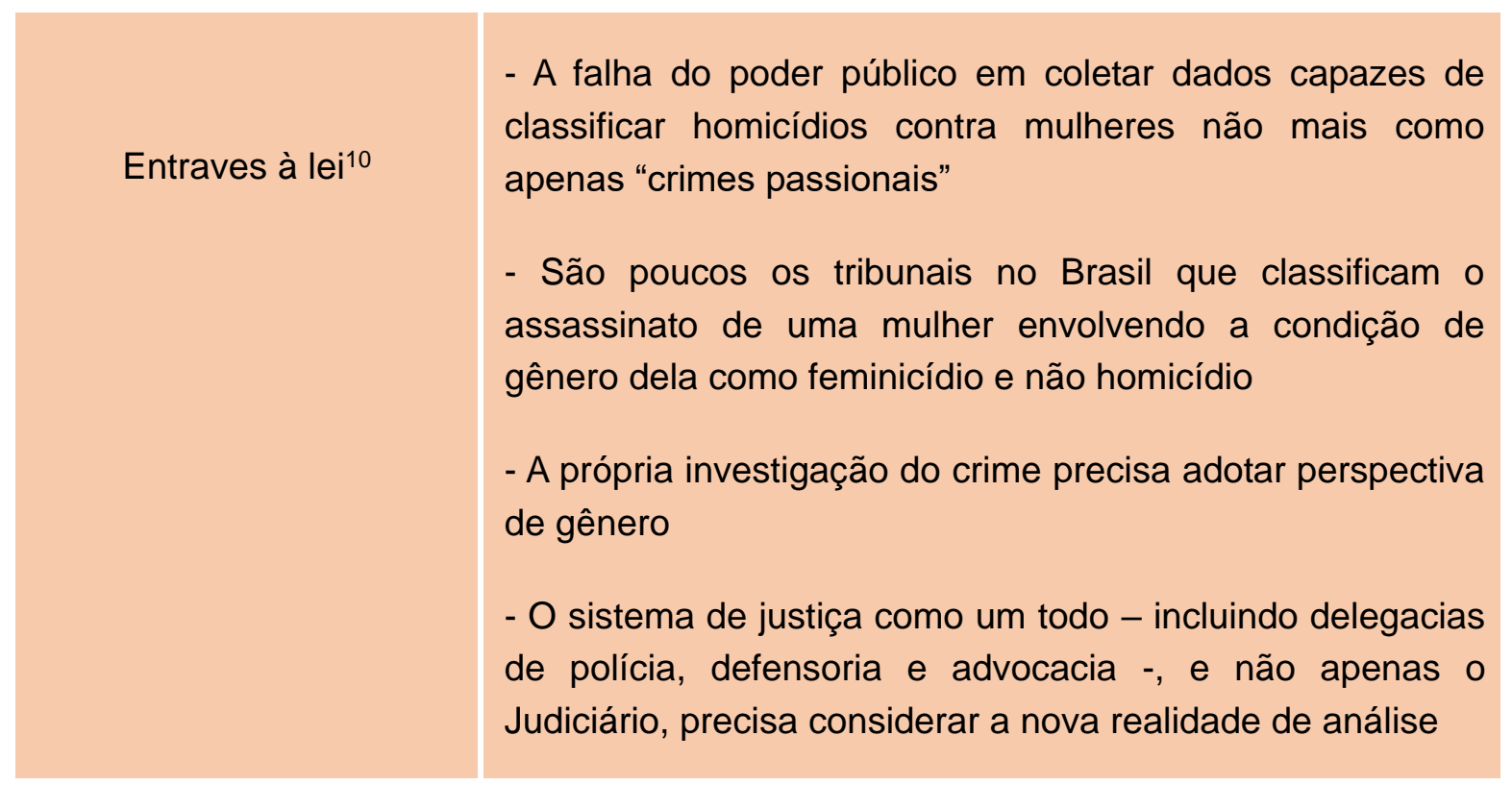

Fonte: Autoria própria.

Portanto, a questão é atual e relevante socialmente e embora haja esforços pontuais dos poderes públicos para coibir a violência de gênero, através de leis e políticas públicas, essas medidas geralmente demoram a provocar mudanças profundas na sociedade. A atenção conferida pela imprensa a estas questões costuma ser um importante catalisador neste sentido, conforme foi possível ver no caso da Lei Maria da Penha ( $\mathrm{n}$. 11.340/2006), que trata de violência doméstica, amplamente divulgada e, por isso, hoje conhecida por grande parte dos brasileiros, ainda que não profundamente.

Os meios de comunicação, se não são determinantes como já se pensou um dia, continuam a ser considerados relevantes para a construção da percepção do público sobre as questões. Sarmento (2017) recobra, no trecho a seguir, o pensamento de Antunes e Vaz (2006) a este respeito.

Os meios de comunicação também são espaços de construção do que Antunes e Vaz (2006, p. 50) chamam de "fala pública", que "não é o somatório das falas isoladas dos indivíduos, nem é a fala coletiva e

\footnotetext{
9 G1 PE. Governo de PE institui termo 'feminicídio' em boletins de ocorrência de homicídios motivados por gênero. G1, Pernambuco, 04 set. 2017. Disponível: https://glo.bo/2IVIhHh. Acesso em: 04 set. 2017.

10 GARCIA, Janaína. Após 2 anos da lei, feminicídio ainda esbarra no machismo, diz juíza. UOL, São Paulo, 11 mar. 2017. Disponível: https://bit.ly/2mw5Aeg. Acesso em: 02 set. 2017.
}

Revista Pauta Geral-Estudos em Jornalismo, Ponta Grossa, vol. 6, n. 2, p. 70-89, Jul/Dez, 2019. 


\title{
REVISTA PAUTA GERAL
}

\section{ESTUDOS EM JORNALISMO}

\author{
10.5212/RevistaPautaGeral.v.6.i2.0005
}

\begin{abstract}
organizada dos agrupamentos sociais, nem é a fala soberana dos meios de comunicação". É a convergência de todas elas, em graus de força diferentes, que se colocam em "permanente circulação e rebatimento, instando os sujeitos a se tornarem seus interlocutores" (Antunes e Vaz, 2006, p. 50), em processos de contestação, resistência, crédito e descrédito. Nessa perspectiva, por nós compartilhada, o jornalismo tem uma importância central não na disseminação de informações em via de mão única, mas pela possibilidade de acionar, a partir dos acontecimentos noticiados, quadros de referências dos sujeitos, correlações com suas experiências pessoais, que se conectam ou se afastam daqueles projetados na mídia (SARMENTO, 2017, p. 65).
\end{abstract}

Haja vista as considerações acima, o presente artigo tem interesse na cobertura do feminicídio a fim de verificar se a Lei sobre este crime, enquanto marco inicial de uma problematização na sociedade sobre um dos mais graves tipos de violência de gênero, produziu algum efeito nos enquadramentos das notícias sobre feminicídio desde que entrou em vigor. Para isto, foi também importante descobrir quais eram os mais frequentes anteriormente, já que as transformações de enquadramentos são visíveis a partir de um distanciamento temporal.

A fim de identificar os framings noticiosos neste tipo de cobertura, optou-se por buscar matérias no caderno Cotidiano da Folha de S. Paulo, que, na definição do próprio jornal, "oferece ao leitor informações úteis ao seu dia-a-dia nas áreas de segurança, educação e direito do consumidor, trazendo diariamente notícias relativas às principais capitais do país". Após o estudo de dezenas de unidades de análise retiradas das páginas deste caderno durante oito anos (de 2004 a 2007 e de 2014 a 2017), os resultados sugerem alguma mudança nos enquadramentos noticiosos sobre este tema.

\section{Enquadramento}

O enquadramento (framing) é um conceito que foi trazido da Sociologia para os estudos de Comunicação para se referir às propriedades que constroem as representações jornalísticas, porém, como lembra Soares (2006), sob uma perspectiva sociocultural e política, não intencionando fazer um questionamento da atuação profissional dos autores das matérias. É uma das perspectivas teóricas mais utilizadas atualmente nos estudos de Comunicação, inclusive no Brasil, onde vem recebendo atenção desde os anos 1990, especialmente em trabalhos sobre a cobertura jornalística de eleições e de movimentos sociais (PORTO, 2004 apud SOARES, 2006, p. 450).

Em 1974, em sua obra Frame Analysis, Erving Goffman definiu os 2019. 


\section{REVISTA PAUTA GERAL}

\section{ESTUDOS EM JORNALISMO}

10.5212/RevistaPautaGeral.v.6.i2.0005

enquadramentos como marcos interpretativos construídos socialmente, permitindo às pessoas atribuírem sentido aos acontecimentos e às situações sociais, de modo a entenderem o que está acontecendo. É, portanto, um processo de definição de situação, implicando na construção de sentido para os eventos cotidianos. Nos estudos de comunicação, este conceito foi introduzido pela socióloga Gaye Tuchman. Em Making News (1978), a autora argumenta que o enquadramento é uma característica essencial das notícias, definindo a realidade e orientando o entendimento da vida contemporânea. Todd Gitlin, em The whole world is watching (1980), propôs uma definição de enquadramento que seria a base para diversos estudos sobre a sua produção na mídia, defendendo que são úteis na organização do mundo de quem escreve sobre ele (os jornalistas) e de quem recorre às notícias (o público): "Enquadramentos da mídia são padrões persistentes de cognição, interpretação e apresentação, de seleção, ênfase e exclusão, através dos quais os manipuladores de símbolos organizam o discurso, seja verbal ou visual, de forma rotineira" (GITLIN, 1980, p.7 apud SOARES, 2006, p. 451).

Entman (1993), autor de textos clássicos sobre esta teoria, afirma que o enquadramento expõe o poder de um texto comunicativo. Este conceito pode estar em quatro lugares durante o processo de comunicação: no comunicador, no texto, no receptor e na cultura. Ele separa os enquadramentos em dois níveis (ENTMAN, 1991): um primeiro de esquemas e mapas mentais que os jornalistas usam para processar a informação; um segundo de características do texto noticioso propriamente dito. Neste último caso, considerado o segundo nível de agenda setting, os enquadramentos são propriedades específicas da narrativa noticiosa que promovem percepções e compreensões sobre os eventos, constituídas por palavras, metáforas, conceitos, símbolos, ironias, imagens visuais, fontes, insinuações e sugestões contidas na narrativa noticiosa. A frequência de determinados enquadramentos promove mais certas ideias, menos outras, enquanto algumas ficam completamente invisíveis.

Para Entman, as características primordiais do enquadramento são a seleção e o destaque:

Enquadramento essencialmente envolve seleção e destaque. Enquadrar é selecionar alguns aspectos de uma realidade percebida e fazê-los mais destacados num texto comunicativo, de maneira a promover uma definição de um problema particular, interpretação causal, avaliação 


\section{REVISTA PAUTA GERAL}

\section{ESTUDOS EM JORNALISMO}

10.5212/RevistaPautaGeral.v.6.i2.0005

moral, e/ou recomendação de tratamento para o item descrito ${ }^{11}$ (ENTMAN, 1993, p. 52).

Por destaque, ele entendia o ato de tornar um aspecto mais noticiável, significativo e memorável ao público, o que pode acontecer através de diversas maneiras: da repetição da informação; da associação dela com algum símbolo cultural que é familiar; do modo de disposição; etc.

Há ainda situações peculiares na produção do enquadramento, como a cobertura de novos eventos que rompem a cobertura cotidiana (ENTMAN, 1991), que tendem a ter o seu enquadramento definido a partir da interação entre jornalistas e fontes.

Gamson e Modigliani (1989 apud GONÇALVES, 2005, p.161) situam o enquadramento na quarta etapa dos estudos dos media effects, iniciada no começo dos anos 1980. Esta etapa reconhece ao mesmo tempo capacidades limitadas e poderosas nos efeitos dos media, ou seja, que existe uma "influência negociada", pois, ao processar e interpretar a realidade social, os indivíduos também levam suas experiências diretas, a interação com seus pares e, assim, fazem interpretações seletivas das mensagens midiáticas. Mas Soares (2006) lembra que há situações nas quais as orientações dos enquadramentos são difíceis de serem detectadas, pois muitos artifícios podem parecer "naturais", embora, ao compará-los com outros textos, fique evidente que estas escolhas não são inevitáveis ou não questionáveis.

E apesar da tendência do enquadramento de favorecer o status quo, ele não é fixo, estando suscetível aos jogos de força sociais. Como explica Soares:

[...] se desenvolvem ao longo do tempo, à medida que os jornalistas redefinem os assuntos e as elites reestruturam suas próprias definições, em razão da mudança das condições políticas, absorvendo ou cooptando enquadramentos dos desafiadores. Assim, alguns assuntos e seus enquadramentos podem mudar do campo inconteste para o campo contestado do discurso jornalístico, por meio dos esforços de desafiadores, entre os quais se encontram os movimentos sociais (SOARES, 2006, p. 454).

Entman (1993) considera que os enquadramentos podem ser detectados pelo

\footnotetext{
11 Framing essentially involves selection and salience. To frame is to select some aspects of a perceived reality and make them more salient in a communicating text, in such a way as to promote a particular problem definition, causal interpretation, moral evaluation, and/or treatment recommendation for the item described.
} 2019. 


\section{REVISTA PAUTA GERAL}

\section{ESTUDOS EM JORNALISMO}

10.5212/RevistaPautaGeral.v.6.i2.0005

modo como os dispositivos deles definem problemas, fazem diagnósticos, julgamentos morais e sugerem soluções. Entretanto, como pontua Soares (2006), não há uma unidade metodológica neste campo de pesquisa, visível pela variedade de concepções dos dispositivos de enquadramento que encoraja os pesquisadores a utilizarem métodos analíticos diversificados para identificar dispositivos de enquadramentos nas notícias.

\section{Metodologia}

A produção do jornal Folha de S. Paulo foi selecionada para este estudo por ser, além de um veículo de alcance nacional e de credibilidade reconhecida, agendando inclusive outros veículos jornalísticos, o de maior circulação paga do Brasil, segundo o Instituto Verificador de Comunicação (IVC). A princípio, foram selecionados os anos de 2015 (de sanção da lei), 2014 (anterior), 2016 (posterior) e 2017 (atual). Mas para verificar uma possível mudança de enquadramento era importante um distanciamento temporal entre os anos de análise, portanto foram acrescentados períodos com uma década de diferença, ou seja, os anos de 2004, 2005, 2006 e 2007.

A coleta das matérias foi realizada através do emprego de palavras-chave relacionadas ao tema ${ }^{12}$ na busca do site do Acervo Folha, que disponibiliza as edições impressas da Folha de S. Paulo digitalizadas. Selecionaram-se textos noticiosos, publicados no caderno Cotidiano nos anos já citados, entre $1^{\circ}$ de janeiro e 31 de dezembro, com a exceção de 2017, que foi limitado de $1^{\circ}$ de janeiro a 31 de agosto.

Após a seleção, foram reunidas as matérias sobre casos que se enquadravam na definição de feminicídio. Estas foram catalogadas e seus dados foram agrupados e analisados a fim de se obter os resultados que serão apresentados mais adiante. Nas matérias, observaram-se os seguintes dados: página de publicação, posição na página e data de publicação; título e subtítulo; autoria; elementos do lead; valor-notícia (SILVA, 2014); fontes das matérias (GUERRA, 2005); palavras-chave; enquadramento(s) noticioso(s). Alguns destes elementos, apesar de não serem centrais para a identificação dos enquadramentos, foram incluídos, pois poderiam revelar algum dado relevante sobre

12 Como este tipo de crime ainda não foi popularizado como feminicídio, foi preciso recorrer a várias palavras-chave como: "feminicídio"; "matou namorada"; "matou esposa"; "mulher morta"; "mulher crime"; "ex morta"; "ex homicídio". O vocábulo "feminicídio" aparece pela primeira vez na Folha de S. Paulo (levando-se em conta todos os cadernos) uma vez em 2014. Em 2015 foram 21 vezes; em 2016, nove; e em 2017, até 31 de agosto, 16 vezes.

Revista Pauta Geral-Estudos em Jornalismo, Ponta Grossa, vol. 6, n. 2, p. 70-89, Jul/Dez, 2019. 
REVISTA PAUTA GERAL

\section{ESTUDOS EM JORNALISMO}

10.5212/RevistaPautaGeral.v.6.i2.0005

a cobertura.

Para os valores-notícias - qualidade que torna um fato importante de ser noticiado -, usou-se a sistematização de Silva (2014), que os organiza nas seguintes categorias ${ }^{13}$ : impacto; proeminência; conflito; tragédia/drama; justiça; proximidade; raridade; surpresa; governo; polêmica; entretenimento/curiosidade; conhecimento/cultura. A classificação de Guerra (2005) foi usada para organizar as fontes citadas nas matérias. Este autor as divide em quatro tipos: envolvidas; autorizadas; testemunhais; qualificadas. As envolvidas são as pessoas que participam diretamente do evento, mas não estão representando instituições. Podem ser divididas em dois tipos: as que praticam a ação que originou o fato; as que são relacionadas de forma passiva a ele e sofrem as consequências do fato que é objeto da matéria jornalística. As fontes autorizadas representam uma instituição ou organização e também se dividem em dois grupos: as reativas, que são convocadas por outras fontes ou pelo próprio jornalista na matéria jornalística e as ativas, divulgadoras ou promotoras de ações que resultam no fato objeto da cobertura. As testemunhais, como o próprio nome indica, presenciaram o fato e não necessariamente têm relação com o acontecimento; a única motivação é "contar o que viu". Já as qualificadas são aquelas com conhecimentos específicos sobre o acontecimento. O papel delas é ajudar a compreendê-lo de forma mais contextualizada.

O número da página na qual foi publicada a matéria e a posição desta, assim como a autoria, ajudaram a compreender a importância dada pelo jornal a este tipo de cobertura. Título e subtítulo, o lead e as fontes auxiliaram diretamente na definição do tipo de enquadramento preponderante na notícia, assim como a ocorrência de eventos importantes durante 0 ano que contribuíram para a presença maior de certos

$13 \mathrm{Na}$ classificação sugerida por Silva (2014), esses critérios significam as seguintes situações: Impacto é quando há um número grande de pessoas envolvidas no fato, afetadas pelo fato ou grandes quantias de dinheiro; Proeminência é notoriedade, celebridade, posição hierárquica, elite (indivíduo, instituição, país), sucesso/herói; Conflito acontece quando há guerra, rivalidade, disputa, briga, greve, reivindicação; Tragédia/drama é catástrofe, acidente, risco de morte e morte, violência/crime, suspense, emoção, interesse humano; Proximidade é geográfica ou cultural; Raridade é o acontecimento incomum, original e inusitado; Surpresa é o fato inesperado; Governo abrange interesse nacional, decisões e medidas, inaugurações, eleições, viagens e pronunciamentos; Polêmica é um valor quando há controvérsia e escândalo; Justiça ocorre quando há julgamentos, denúncias, investigações, apreensões, decisões judiciais e crimes; Entretenimento/curiosidade quer dizer aventura, divertimento, esporte e comemoração; Conhecimento/cultura significa descobertas, invenções, pesquisas, progresso, atividades e valores culturais e religião.

Revista Pauta Geral-Estudos em Jornalismo, Ponta Grossa, vol. 6, n. 2, p. 70-89, Jul/Dez, 2019. 


\section{REVISTA PAUTA GERAL}

\section{ESTUDOS EM JORNALISMO}

10.5212/RevistaPautaGeral.v.6.i2.0005

enquadramentos. Algumas matérias, aliás, apresentaram mais de um enquadramento, que só foram considerados quando realmente isso era relevante. Os resultados obtidos serão apresentados na seção a seguir.

\section{Resultados}

Ao todo, foram reunidas 100 unidades de análise nos oito anos pesquisados, uma média de 12,5 por ano. Este número variou pouco em cinco anos, apresentando diferenças em 2006 (116\% superior à média anual), 2015 e 2016 (reunindo, cada, 24\% da média anual). O primeiro bloco de anos (2004-2007) concentrou dois terços das matérias. A incidência de mais de um enquadramento ocorreu em apenas $12 \%$ do material analisado.

Nos primeiros quatro anos (2004-2007), o enquadramento policial foi identificado em $50 \%$ das matérias, seguido do judicial $(25,6 \%)$ e do drama familiar (13,5\%), enquanto os demais corresponderam a pouco mais que $1 \%$ do total. Os enquadramentos encontrados nos quatro últimos anos (2014-2017) foram os seguintes: policial $(55,2 \%)$; judicial $(13,15 \%)$; drama familiar (13,15\%); violência de gênero $(5,26 \%)$; político $(5,26 \%)$; outros $(7,89 \%)$.

\section{Gráfico 1 - Principais enquadramentos encontrados por quadriênio}




\section{REVISTA PAUTA GERAL}

\section{ESTUDOS EM JORNALISMO}

10.5212/RevistaPautaGeral.v.6.i2.0005

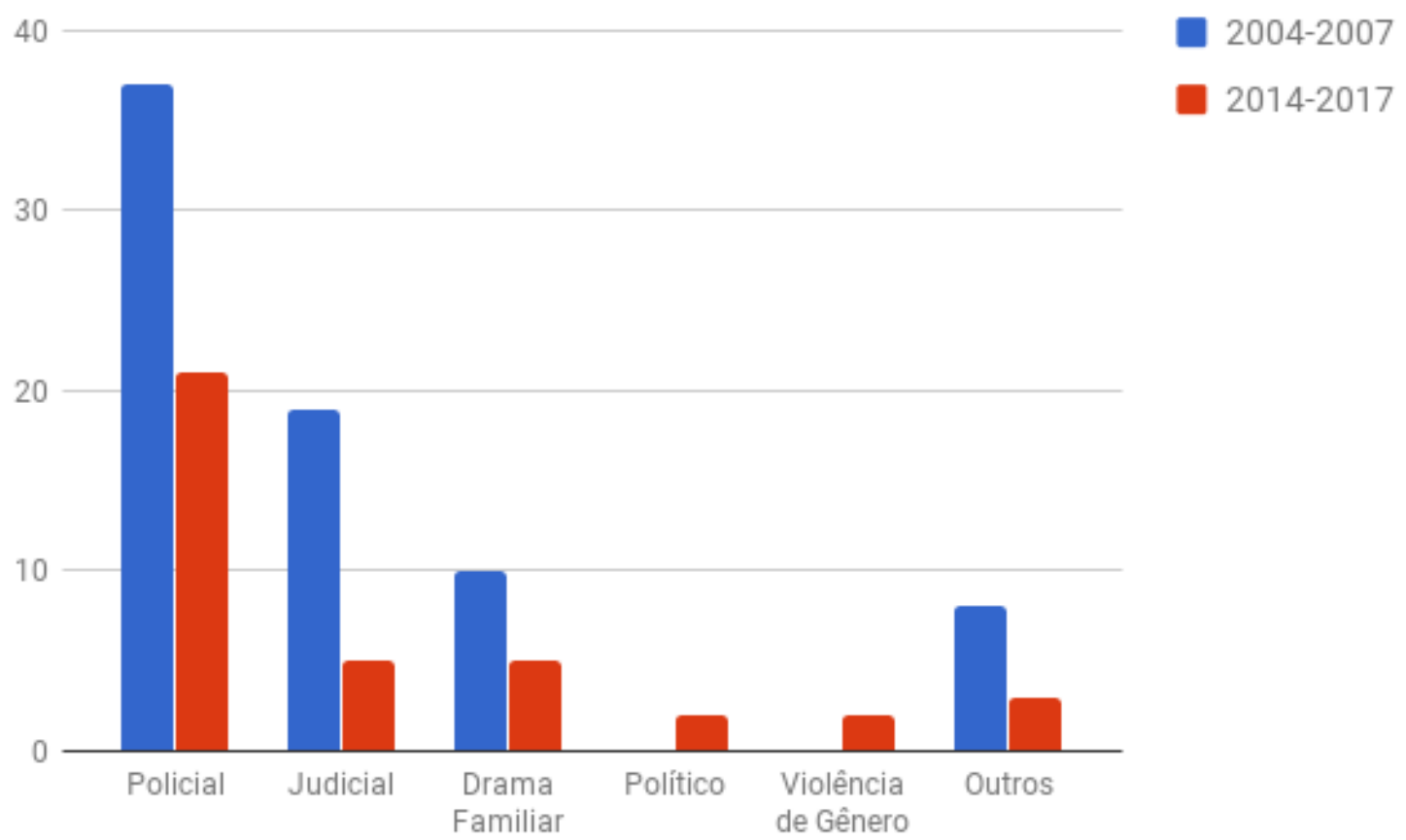

No total da amostra analisada foram encontrados 13 tipos de enquadramentos, com predominância dos seguintes: policial (51,78\%); judicial (21,42\%); drama familiar (13,39\%); político (2,67\%); violência de gênero $(2,67 \%)$; moral $(1,78 \%)$; outros $(6,25 \%)$. Serão descritos a seguir aqueles que tiveram pelo menos $1 \%$ de presença na amostra. Juntos, estes seis enquadramentos responderam por $93,18 \%$ do material deste estudo.

\section{Gráfico 2 - Número total de ocorrências dos enquadramentos}


REVISTA PAUTA GERAL

ESTUDOS EM JORNALISMO

10.5212/RevistaPautaGeral.v.6.i2.0005

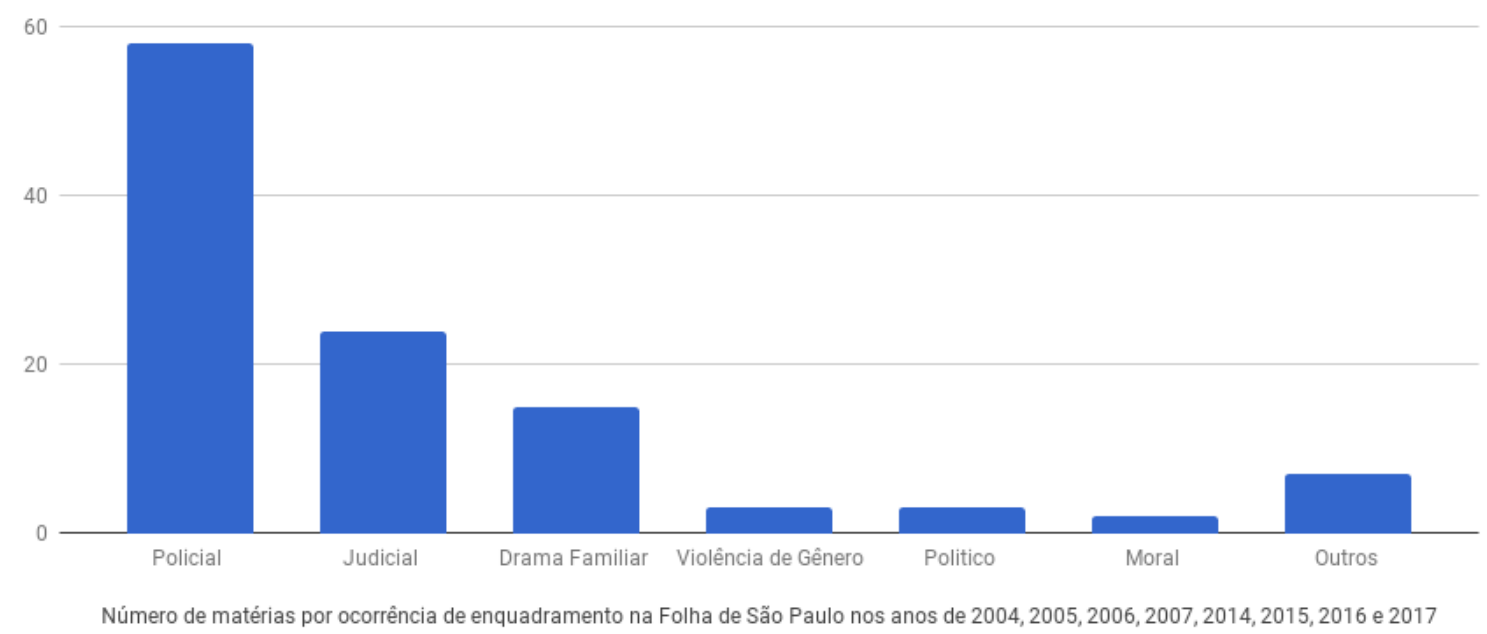

O enquadramento policial apresenta o acontecimento através da investigação policial, destacando frequentemente detalhes sobre o crime. A matéria costuma ser construída a partir das informações de delegados, policiais, conhecidos da vítima e do assassino ou testemunhas do crime. Portanto, há frequência de fontes autorizadas, envolvidas e testemunhais, com maior recorrência do primeiro grupo. O valor-notícia preponderante aqui é tragédia/drama. Algumas palavras-chave frequentemente encontradas durante os anos analisados foram: "ex"; "inconformado"; "assassinato"; "suspeito"; "passional"; "ciúmes".

Este enquadramento foi o único que apareceu em todos os anos da amostra trabalhada neste artigo e correspondeu a $55,23 \%$ dos que foram identificados nas matérias: 2004 (61,5\%); 2005 (66,6\%), 2006 (29,6\%), 2007 (91,6\%), 2014 (66,6\%), 2015 (33,3\%), 2016 (100\%), 2017 (58,3\%).

Um exemplo deste framing está em uma nota publicada em 2004, iniciada assim:

Por razões passionais e de forma premeditada, segundo a polícia, Manoel Rodrigues da Silva, 23, matou a tiros quatro pessoas ontem, em Três Lagoas (MS), cidade de cerca de 80 mil habitantes (RAPAZ mata exnamorada e três homens, Folha de S. Paulo, São Paulo, 09 mar. 2004, caderno Cotidiano, página 3).

O enquadramento judicial tem como eixo narrativo o desdobramento do feminicídio na Justiça. Aparece quando há julgamento, sentença, enfim, qualquer novidade sobre o processo do caso. Geralmente envolve o valor-notícia proeminência - uma das partes 2019. 


\section{REVISTA PAUTA GERAL}

\section{ESTUDOS EM JORNALISMO}

10.5212/RevistaPautaGeral.v.6.i2.0005

envolvidas no fato possui destaque social -, além do valor justiça. Aqui, as vozes mais frequentes são as de fontes autorizadas, como advogados, promotores, tribunais, etc. As palavras-chave frequentes aqui foram: "defesa"; "acusação"; "crime"; "julgamento"; "condenado"; "assassinato"; "pena"; "ex"; "mulher". Identificado em 22,85\% das matérias analisadas, esteve presente em cinco dos oito anos: 2004 (23\%); 2005 (20\%); 2006 (48,1\%); 2014 (20\%); 2017 (16,6\%).

Uma cobertura que privilegiou este enquadramento foi a do caso Pimenta Neves.

No segundo dia do julgamento do jornalista Antonio Marcos Pimenta Neves, 69, os advogados de defesa tentaram demonstrar aos jurados que ele sofria de estresse emocional que 0 deixou confuso $e$ desorientado na época do crime. Já a acusação sustentou a tese de que o assassinato da jornalista Sandra Gomide, 32, ex-namorada dele, foi premeditado (DEFESA vê trauma; acusação, crime premeditado, Folha de S. Paulo, São Paulo, 05 mai. 2006, caderno Cotidiano, página 4).

O terceiro enquadramento mais frequente foi o de drama familiar $(7,61 \%)$, geralmente concentrando a narrativa da matéria no drama humano, destacando o significado da morte trágica da vítima para os seus familiares. Nas matérias analisadas, com frequência a vítima ou assassino tinha proeminência social, sendo comum, além deste valor-notícia, também tragédia/drama e justiça. As fontes ouvidas são geralmente dos tipos envolvida e autorizada, com destaque para o primeiro grupo, representado pelos parentes ou amigos próximos da vítima, como as palavras-chave encontradas podem evidenciar: "família"; "pai”; "mãe"; "justiça”; "filha”; "assassinada”; "matou”; "juiz".

O drama familiar só não foi identificado em 2007 e 2016, tendo a seguinte participação nos demais anos: 2004 (7,7\%); 2005 (6,6\%); 2006 (29,6\%); 2014 (13,3\%), 2015 (33,3\%); 2017 (16,6\%).

"A mãe dela dizia que vivia apenas para encontrar a filha", relata a administradora de empresas Jucélia Lisboa, amiga da família da turista israelense Katryn Rakitov ("MÃE esperava encontrar a filha", diz amiga, Folha de S. Paulo, São Paulo, 01 abr. 2005, caderno Cotidiano, página 8).

O enquadramento politico apresentou uma baixa frequência (2,85\%) e praticamente figurou apenas em 2015 (ano que reuniu 66,6\% do total de matérias identificadas com este framing, que representou $66,6 \%$ dos enquadramentos daquele 


\section{REVISTA PAUTA GERAL}

\section{ESTUDOS EM JORNALISMO}

10.5212/RevistaPautaGeral.v.6.i2.0005

período), quando o projeto da Lei do Feminicídio foi votado e sancionado. A outra ocorrência foi em 2004 (com 7,7\% dos enquadramentos daquele ano), como segundo enquadramento mais importante em uma matéria com enfoque policial.

O enquadramento político destaca o feminicídio sob o ponto de vista das articulações e disputas entre os atores políticos e partidos, da aprovação de leis e do posicionamento destes atores sobre a questão. As fontes ouvidas costumam ser as autorizadas, como presidentes de comissões e líderes de partidos. Foram identificadas ainda fontes qualificadas e testemunhais, porém este último tipo ocorreu apenas uma vez. A quantidade de valores-notícia relacionada às matérias foi maior que em outros framings: governo; proeminência; impacto; tragédia/drama; justiça. As palavras-chave também, incluindo pela primeira vez o termo que caracteriza este tipo de homicídio: "candidato"; "morta”; "crime"; "vítima”; "feminicídio"; "Câmara”; "projeto"; "violência doméstica".

A Câmara dos Deputados aprovou nesta terça-feira (3) projeto que inclui no Código Penal o "feminicídio", pelo qual matar uma mulher por razões de gênero, como no caso de violência doméstica, passa a ser agravante do crime de homicídio (CÂMARA aprova feminicídio como agravante para a morte, Folha de S. Paulo, São Paulo, 04 mar. 2015, caderno Cotidiano, página 7).

Assim como o enquadramento político, o de violência de gênero faz parte do grupo dos menos frequentes na amostra (2,85\%), sendo identificado apenas em 2006 (3,7\%), como enquadramento secundário, e em 2017 (16,6\%), desta vez alternando entre principal e secundário. Destaca o feminicídio como produto de um contexto de desigualdade de gênero, que gera a violência contra a mulher. As fontes usadas foram do tipo qualificada, geralmente especialistas e representantes de instituições e organismos envolvidos com o combate à violência contra a mulher e na promoção da igualdade de gênero. Também foram ouvidas fontes autorizadas, já que este enquadramento surgiu junto com o policial nas matérias analisadas. Aqui, predominaram valores-notícia de impacto, tragédia/drama e justiça e as seguintes palavras-chaves: "especialista"; "assassinadas"; "mulheres"; "companheiros"; "vítima"; "feminicídio"; "lei".

Como geralmente este enquadramento aparece após a exposição de um crime ou da situação de segurança de uma localidade, o trecho destacado para ilustrá-lo é o primeiro parágrafo após o intertítulo da matéria, recurso utilizado para separar diferentes aspectos da notícia:

Revista Pauta Geral-Estudos em Jornalismo, Ponta Grossa, vol. 6, n. 2, p. 70-89, Jul/Dez, 2019. 
REVISTA PAUTA GERAL

ESTUDOS EM JORNALISMO

10.5212/RevistaPautaGeral.v.6.i2.0005

\begin{abstract}
Tudo indica que, no país como um todo, o quadro do feminicídio é ainda pior. Uma pesquisa do Ipea que estimou o número de ocorrência com base nos registros de saúde de 2009 a 2011 indicou que São Paulo tinha a terceira menor taxa do Brasil - 3,2 a cada 100 mil mulheres, contra 11,2 do Espírito Santo, que lidera o ranking (SP registra 1 caso de feminicídio a cada 4 dias, Folha de S. Paulo, São Paulo, 23 ago. 2017, caderno Cotidiano, página 1).
\end{abstract}

O enquadramento moral centra a narrativa na vida íntima e nas condutas da vítima e do assassino, induzindo o leitor a realizar um julgamento moral de ambos. Além dos valores-notícia mais recorrentes até agora, de tragédia/drama e justiça, este framing também esteve associado ao de proeminência. Fontes dos tipos envolvida e autorizada foram identificadas nas matérias, assim como ocorreram as seguintes palavras-chave: "assassinato"; "ex-namorada"; "trauma"; "transtorno"; "premeditado"; "estresse"; "crime"; "depressão"; "ciúmes". Com a menor presença entre todos os enquadramentos descritos nesta seção (1,79\%), ocorrendo somente em 2006 (3,7\%) e 2017 (16,6\%), também foi identificado em matérias nas quais dividia espaço com o enquadramento policial. Por este motivo, o trecho destacado aqui corresponde aos dois últimos parágrafos antes do primeiro intertítulo da matéria - oitavo e nono - quando o texto abandona a narrativa policial e começa a destrinchar as características das personalidades dos envolvidos:

Sozinho na cidade, apaixonou-se por Mara. Terminou um casamento de 24 anos, do qual tem uma filha de 23 e um garoto de 10 anos, e foi morar com a jovem na Enseada do Suá, bairro nobre de Vitória, num apartamento pago pela firma.

Foi nesse período que presenteou Mara com um Chevrolet Cruze e the pagou uma cirurgia estética no nariz com um especialista renomado do Rio - "um sonho dela", dizia (CAMINHO de um crime, Folha de S. Paulo, São Paulo, 15 jan. 2017, caderno Cotidiano, página 4).

\title{
Gráfico 3 - Enquadramentos identificados nas matérias por ano
}




\section{REVISTA PAUTA GERAL}

\section{ESTUDOS EM JORNALISMO}

10.5212/RevistaPautaGeral.v.6.i2.0005

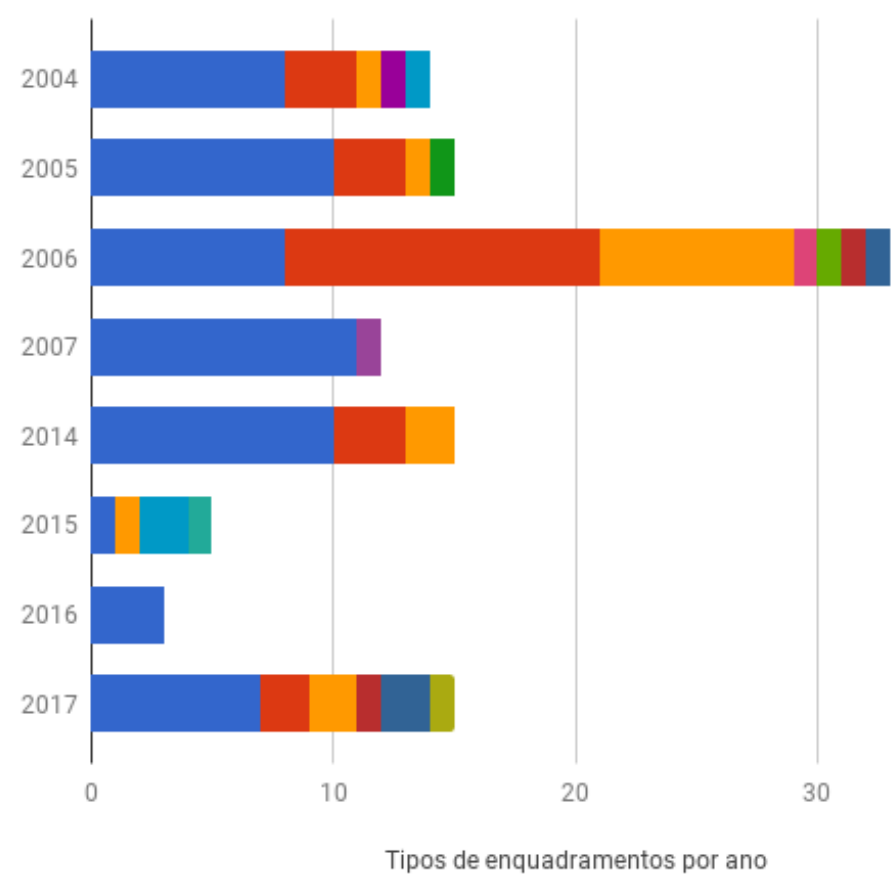

Policial

Judicial

Drama Familiar

Drama pessoal

Religioso

Político

Celebridade

Diplomático

Moral

Violência de gênero

Impunidade

Conquista das mulheres

Doença

40

\section{Conclusões}

Neste artigo estudou-se a cobertura de feminicídios na Folha de S. Paulo durante oito anos das duas últimas décadas, a partir da teoria do enquadramento, a fim de descobrir quais são os tipos mais recorrentes nesta cobertura e se a alteração na legislação, em 2015, havia provocado alguma mudança a este respeito. Assim, a partir de uma metodologia quantitativa e qualitativa, foram identificados seis tipos mais recorrentes de enquadramentos, com predominância de apenas dois deles - policial e judicial -, respaldados no uso de fontes autorizadas.

Apesar da alta quantidade de registros de feminicídios no Brasil, como foi possível observar nos dados trazidos na introdução deste artigo, a média mensal de matérias sobre o assunto registrada na pesquisa - 1,08 - demonstra que a questão ainda parece ser pouco agendada pelos jornais - ou pelo menos este é o caso da Folha no período estudado. Desde os anos 1970, os movimentos de mulheres apontam esses assassinatos como produtos do patriarcado e, deste modo, o reconhecimento da existência dos feminicídios significa mais do que uma troca de palavras, como observa Gomes (2018):

Chamar de feminicídio um fato que é produto de um conjunto de violências pregressas, e que compreende: letalidade, desigualdade de 


\title{
REVISTA PAUTA GERAL
}

\section{ESTUDOS EM JORNALISMO}

\author{
10.5212/RevistaPautaGeral.v.6.i2.0005
}

\begin{abstract}
condições, não acidentalidade, intencionalidade em função do gênero do sujeito, e em muitos casos, crueldade e brutalidade, é uma maneira de publicizar, politizar e colocar na ordem do dia o problema da morte violenta de mulheres que constitui um grave fenômeno social, porque coloca em risco mais da metade da população mundial. Neste sentido, dizer feminicídio não é simplesmente substituir um vocábulo por outro (mortes violentas ou assassinato), mas reconhecer um fenômeno e expressar o conjunto de elementos que o conformam e, portanto, revelar uma concepção teórica acerca da realidade (GOMES, 2018, p. 12-13).
\end{abstract}

Além da pouca frequência, a cobertura tendeu a não dar relevância a este tipo de acontecimento: as matérias ocupam um espaço entre pequeno e médio; têm pouco destaque na página; e são poucas as vozes que compõem as narrativas das matérias, sendo a principal delas a policial. Sobre o tamanho e o destaque, geralmente estes são concedidos quando o valor-notícia proeminência aparece, significando que há alguém com relevância social envolvido no caso. Mas a maioria das notícias analisadas (69\%) não se relacionou à proeminência. Apenas $22 \%$ delas estiveram no topo da página e só 9\% ocuparam mais da metade da página ou a página inteira. Conforme foi dito em "Resultados", a proeminência é um valor-notícia relacionado aos enquadramentos de justiça e de drama familiar. Grande parte da sua presença na amostragem ocorreu em 2006 (58\%), e talvez isto explique a maior produção de notícias sobre feminicídio naquele ano, com, aliás, $18,5 \%$ delas na forma de secundárias ${ }^{14}$, indicando o destaque dado pelo jornal a algumas histórias que envolviam personagens de relevância social.

Quanto às fontes, a maioria (58\%) foi do tipo autorizada, enquanto as qualificadas, que indicariam o interesse por uma cobertura mais abrangente e com pluralidade de vozes, representaram apenas $10,5 \%$ do total. Pelo pouco agendamento dado ao tema, é provável que o uso expressivo de fontes autorizadas seja reflexo desta escolha editorial, uma vez que traz praticidade à cobertura, já que estas fontes respondem as perguntas básicas sobre o fato e conferem credibilidade automática à matéria. Com metodologia similar, Francisco (2016) também verificou a predominância de fontes autorizadas. Como ele explica, esse dado reforça algumas questões já elencadas por teóricos dos estudos em jornalismo que atribuem isso à configuração do campo jornalístico, que tem no uso de fontes autorizadas/oficiais um dos elementos para a construção de sua credibilidade (FRANCISCO, 2016, p. 26-28). No entanto, isso contribui para reforçar uma "moldura"

\footnotetext{
14 A matéria secundária é aquela que está relacionada à matéria principal, sendo publicada na mesma página e dando segmento à história, mas sob outro ângulo.

Revista Pauta Geral-Estudos em Jornalismo, Ponta Grossa, vol. 6, n. 2, p. 70-89, Jul/Dez, 2019.
} 


\section{REVISTA PAUTA GERAL}

\section{ESTUDOS EM JORNALISMO}

10.5212/RevistaPautaGeral.v.6.i2.0005

incompleta e parcial sobre estes crimes, se abstendo de contextualizá-los e deslocando as causas e soluções para o indivíduo e não para a estrutura na qual está inserido.

Ao mesmo tempo em que o enquadramento policial cresceu em presença durante o segundo quadriênio, os tipos de enquadramentos tornaram-se um pouco mais diversos neste período. Mas isto não ocorre se considerarmos o número total de enquadramentos encontrados nas 100 unidades analisadas. Dos 13 tipos, 11 aparecem no primeiro bloco temporal e oito, no segundo bloco. Entretanto, se retirarmos a categoria "outros", onde foram computados os enquadramentos que apareceram apenas uma vez, o bloco 20142017 possui maior quantidade de enquadramentos identificados mais de uma vez, a exemplo de "violência de gênero" e "político", computados em "outros" no primeiro quadriênio e mais recorrentes no segundo. Uma hipótese para isto, no caso do framing político, é o fato do período ter coincidido com o da discussão da lei no Congresso, em 2015.

De um modo geral, os enquadramentos identificados nos primeiros sete anos analisados sofreram alterações pontuais motivadas pelas circunstâncias externas, dos próprios fatos cobertos, a exemplo de 2006, que, pelo número de casos envolvendo julgamentos de personagens de destaque social, excepcionalmente apresentou predominância do enquadramento judicial. No entanto, os aspectos destacados na cobertura de feminicídio do jornal começaram a apresentar mudanças no segundo semestre de 2017, mas desta vez indicando, talvez, um redirecionamento no modo de narrar este tipo de fato.

Portanto, é possível que o resultado verificado no início do segundo semestre de 2017 indique uma mudança em curso no perfil de enquadramentos recorrentes neste tipo de cobertura. Essa mudança estaria em consonância com os movimentos realizados, ainda que de forma incipiente, pelo próprio sistema de justiça de readequar o seu olhar sobre o feminicídio, conforme a própria criação da Lei implicitamente já propunha à sociedade brasileira.

\section{Referências}

BARDIN, L. Análise de Conteúdo. Lisboa: Edições 70, 2010.

DA ROSA, Thiana Elisa Bernardi Carvalho. Homicídio Passional: Uma análise criminológica. 2010. 84 f. Trabalho de Conclusão de Curso (Graduação em Direito) Universidade do Vale do Itajaí, Itajaí, 2010. 2019. 


\section{REVISTA PAUTA GERAL}

\section{ESTUDOS EM JORNALISMO}

10.5212/RevistaPautaGeral.v.6.i2.0005

ENTMAN, Robert Mathew. Framing U.S. Coverage of International News: Contrasts in Narratives of the KAL and Iran Air Incidents. Journal of Communication, v. 41, n. 4, p. 627, dez. 1991.

ENTMAN, Robert Mathew. Framing: Toward Clarification of a Fractured Paradigm. Journal of Communication, v. 43, n. 4, p. 51-58, dez. 1993.

FRANCISCO, Eduardo Pereira. Enquadrando a diferença: análise dos frames sobre identidades LGBT nos jornais Folha de S. Paulo e o Globo. 2016. 334 f. Dissertação (Mestrado em Comunicação) - Universidade Federal da Bahia, Salvador, 2016.

GOMES, Izabel Solyszko. Feminicídios: um longo debate. Revista Estudos Feministas, Florianópolis, v. 26, ed. 2, 11 jun. 2018. Disponível em: encurtador.com.br/fjoCV. Acesso em: 14 nov. 2019.

GONÇALVES, Telmo. A abordagem do enquadramento nos estudos do jornalismo. Caleidoscópio - Revista de Comunicação e Cultura, Lisboa, n.ำ 5/6 (2005), p. 157-167, jul. 2011.

GUERRA, Josenildo Luiz. Fontes de informação nos telejornais sergipanos. In: Encontro Nacional de Pesquisadores em Jornalismo, 3, 2005, Florianópolis. Anais do III Encontro Nacional de Pesquisadores em Jornalismo. Florianópolis: UFSC, 2005.

LAGARDE, Marcela. Antropología, feminismo y política: violência feminicida y derechos humanos de las mujeres. In: BULLEN, M.; MINTEGUI, C. D. (Orgs.). Retos teóricos y nuevas prácticas. Serie, XI Congreso de Antropología de la FAAEE. Donostia: Ankulegi Antropologia Elkartea, 2008, p. 209-239.

SARMENTO, Rayza. Mídia, política e feminismo. In: SARMENTO, Rayza. Das sufragistas às ativistas 2.0: feminismo, mídia e política no Brasil (1921 a 2016). 2017. 220 f. Tese (Doutorado em Ciência Política) - Universidade Federal de Minas Gerais, Belo Horizonte, 2017, p. 50-78.

SILVA, Gislene. Para pensar critérios de noticiabilidade. In: SILVA, G.; SILVA, M. P. da; FERNANDES, M. L. (Orgs.). Critérios de noticiabilidade: problemas conceituais e aplicações. Florianópolis: Insular, 2014, p. 51-69.

SOARES, Murilo César. Análise de Enquadramento. In: BARROS, A.; DUARTE, J. (Orgs.). Métodos e Técnicas de Pesquisa em Comunicação. São Paulo: Editora Atlas S.A., 2006, p. 450-465.

Recebido em: 15/10/2019

Aprovado em: 22/11/2019 